ARTIGOS

ESPAÇO, ECONOMIA E POPULAÇÃO

\title{
DINÂMICA REGIONAL DA INDÚSTRIA DE TRANSFORMAÇÃO NO BRASIL (2000-2017)
}

\author{
Cássio Garcia Ribeiro* \\ Soraia Aparecida Cardozo* \\ Humberto Martins* \\ *Universidade Federal de Uberlândia, Instituto de Economia e Relações Internacionais, Uberlândia, MG, Brasil
}

\begin{abstract}
Resumo
Este trabalho tem como objetivo analisar a dinâmica regional da indústria de transformação no Brasil no período recente, por meio de um exame conjunto das alterações na estrutura produtiva e nas características desse setor nas cinco macrorregiões do Brasil (Norte, Nordeste, Centro-Oeste, Sudeste e Sul). Considerando o debate recente sobre a temática, são examinadas as mudanças ocorridas no que se refere à importância econômica e no perfil tecnológico da indústria de transformação em cada região. Os resultados indicam que dois fenômenos merecem destaque: i) o recuo da participação da indústria de transformação nas estruturas produtivas das regiões do país; ii) a continuidade da desconcentração regional da indústria de transformação, mas esse processo é lento e não modifica o perfil da divisão inter-regional do trabalho, marcada pelo predomínio do Sudeste nas atividades mais intensivas em Ciência, Tecnologia e Inovação (CT\&I). Busca-se avaliar o significado desses processos para o desenvolvimento econômico do Brasil.

Palavras-chave

Indústria de transformação; Estrutura produtiva; Desenvolvimento regional.
\end{abstract}




\author{
ARTICLES \\ SPACE, ECONOMY AND POPULATION
}

\title{
REGIONAL DYNAMICS OF \\ MANUFACTURING IN BRAZIL (2000-2017)
}

\author{
Cássio Garcia Ribeiro* \\ Soraia Aparecida Cardozo* \\ Humberto Martins* \\ *Universidade Federal de Uberlândia, Instituto de Economia e Relações Internacionais, Uberlândia, MG, Brazil
}

\begin{abstract}
The objective of this article is to analyse the regional and technological dynamics of manufacturing in Brazil in recent period, examining both the changes in productive structure and in manufacturing characteristics in Brazilian five macro-regions (North, Northeast, Centre-West, Southeast and South). Considering the recent debate on this issue, we examine the changes related to the importance and technological characteristics of manufacturing at each region, highlighting the technological intensity, expenditures on innovative activities and introduction of innovations. The outcomes highlight two tendencies: i) the decline of manufacturing in the regional productive structures; ii) the maintenance of manufacturing regional devolution, a slow process that does not modify substantially the interregional profile, marked by a predominance of Science, Technology and Innovation (ST\&I) intensive activities in region Southeast. We try to evaluate the meaning of these changes relating to Brazilian economic development process.

Keywords

Manufacturing; Productive structure; Regional development.
\end{abstract}




\title{
DINÂMICA REGIONAL DA INDÚSTRIA DE TRANSFORMAÇÃO NO BRASIL (2000-2017)
}

\author{
Cássio Garcia Ribeiro \\ Soraia Aparecida Cardozo \\ Humberto Martins
}

Introdução

O objetivo deste artigo é compreender como tem evoluído no período recente a dinâmica regional da indústria de transformação no Brasil. Tal análise é feita em três movimentos: i) observa-se se ela tem reduzido sua participação nas estruturas produtivas regionais; ii) examina-se se a indústria de transformação apresenta uma dinâmica desconcentradora mais intensa que os demais setores; e, por fim, iii) o enfoque se volta para a importância e o perfil produtivo, tecnológico e de inovação da indústria de transformação no âmbito das cinco macrorregiões do Brasil.

A metodologia desta pesquisa se apoia em pesquisa bibliográfica e na análise de dados secundários. Quanto à pesquisa bibliográfica, este estudo tem como principais marcos teóricos: i) a tradição herdada do estruturalismo latino-americano, mais precisamente as contribuições de Celso Furtado acerca do processo de industrialização brasileira; ii) a literatura brasileira em torno da dinâmica regional da indústria de transformação; e iii) a discussão a respeito do fenômeno da desindustrialização, especialmente no contexto dos países subdesenvolvidos. O recorte temporal abarca o período de 2000 a 2017.

Nesse interregno, alternam-se momentos de crescimento, desaceleração e queda acentuada do PIB. Foram utilizadas algumas bases de dados oficiais do Instituto Brasileiro de Geografia e Estatística (IBGE), que contêm séries históricas com indicadores pertinentes para estudos desta natureza, tais como: i) Valor Adicionado Bruto (VAB); ii) Valor da Transformação Industrial (VTI) da indústria de transformação; e iii) investimentos em atividades inovativas e inovações em 
produto e processo. O VAB, além do olhar focado na indústria de transformação, é utilizado para examinar as estruturas produtivas regionais (e brasileira) como um todo. Por outro lado, a análise se restringe à indústria de transformação quando são mencionados os demais indicadores, mediante o exame de distintas trajetórias em nível macrorregional. Além desses indicadores, este estudo apresenta uma investigação apoiada na tipologia de intensidade tecnológica da Organização para Cooperação e Desenvolvimento Econômico (OCDE).

Os resultados deste estudo indicam que nas últimas décadas o Brasil vem passando por um processo de desindustrialização, considerado precoce porque ocorre sem que o país tivesse aproveitado todas as potencialidades da indústria. Além disso, o setor terciário não absorve a queda no setor industrial e, ao contrário da desindustrialização observada nos países desenvolvidos, não se verifica o mesmo movimento de conexão entre os setores da economia. Soma-se a esse processo a expansão das atividades agropecuárias e extrativas minerais (em grande medida voltadas para as exportações), levando a uma especialização regressiva da estrutura produtiva e da pauta exportadora. E, nesse contexto de desindustrialização e especialização regressiva, é possível perceber um processo de desconcentração industrial tímido, que não é capaz de reverter o caráter concentrado da indústria de maior conteúdo tecnológico no Sudeste.

Além desta introdução, este artigo está organizado em mais quatro seções. Na primeira, são apresentadas as tendências do desenvolvimento regional brasileiro no período recente, explorando a bibliografia dessa área temática, sobretudo na discussão da dinâmica regional e das mudanças na estrutura produtiva. A segunda seção analisa conjuntamente as mudanças nessa estrutura e as tendências de desconcentração produtiva, com base na evolução na participação das regiões no VAB nacional, assim como o perfil e as alterações das estruturas produtivas regionais, discutindo a queda de participação da indústria de transformação em quase todas as regiões brasileiras. A terceira seção focaliza o perfil tecnológico da indústria de transformação, com base em indicadores de Ciência, Tecnologia e Inovação trabalhados em nível macrorregional. O objetivo da quarta seção consiste em analisar as tendências, construir hipóteses e problematizar os dados apresentados no artigo acerca da dinâmica (nacional e regional) da indústria de transformação brasileira nas décadas de 2000 e 2010. Por fim, são apresentadas as considerações finais.

1. Industrialização periférica, questão regional e desindustrialização

Por trás do debate sobre as limitações da industrialização pela substituição de importações na América Latina, em particular no Brasil, questões como progresso técnico, distribuição de renda e dispersão regional desse setor são frequentemente 
tratadas pela literatura. De acordo com a interpretação cepalina, os países periféricos, após se industrializarem, não conseguem superar sua heterogeneidade estrutural. Essa situação decorre de vários motivos, tais como: i) inadequação da tecnologia transferida pelos países centrais em relação às especificidades dos países periféricos, visto que a produção envolve alta densidade de capital e inadequação de escala; ii) apresentação, pelo capital privado, de taxas de poupança e de investimento reduzidas; iii) pouca dinamicidade das exportações; iv) quadro de dependência tecnológica causado pelas empresas multinacionais, que se tornam protagonistas nos segmentos industriais mais dinâmicos (BIELSCHOWSKY, 2000).

De acordo com Furtado (1972), deve-se questionar a tese que prevaleceu imediatamente após a Segunda Guerra Mundial, conforme a qual a industrialização constituiria razão suficiente para a superação do subdesenvolvimento. Para ele, a experiência brasileira evidencia a necessidade de que sejam realizados estudos detalhados acerca do processo de industrialização na condição do subdesenvolvimento (FURTADO, 1972, p. 8). Primeiramente, para esse autor, é importante considerar que, durante a etapa de implementação das indústrias de bens de consumo não duráveis, houve certa margem de manobra para os países periféricos do ponto de vista dos processos técnicos com diferentes coeficientes de capital por trabalhador. Todavia, essa margem foi se estreitando ou se tornou inexistente quando esses países iniciaram a fase de substituição dos bens duráveis. Nessa mesma obra, Furtado salienta que, à medida que se expandia mais rapidamente o mercado formado pelas classes mais abastadas, os investimentos tenderam a se concentrar no setor em que, em geral, a dotação do capital por pessoa é mais elevado e as funções de produção apresentam coeficientes mais rígidos.

Nesse sentido, durante a industrialização por substituição de importações (sobretudo durante a fase de substituição de bens duráveis), a função de produção da indústria apresentava como tendência a redução da utilização de mão de obra por unidade do produto. Como a característica da sociedade brasileira é o excedente estrutural de mão de obra, o resultado foi a concentração de renda. Esse fenômeno interferiu no perfil da demanda, especialmente da minoria privilegiada, provocando diversificação em sua pauta de consumo. O resultado foi a redução do crescimento relativo das indústrias caracterizadas por menor coeficiente de capital por trabalhador.

Outra característica do processo de industrialização do país é o fato de que ele gerou e intensificou uma série de desequilíbrios regionais, à medida que os investimentos industriais se concentravam na região Sudeste. Furtado (2009) destaca que a concentração regional da renda é um fenômeno universal e que no Brasil ela tomaria grandes dimensões com o avanço do processo de industrialização. Ademais, 
a articulação das distintas regiões pelo processo de industrialização foi decisiva para a conformação nacional do país. Na segunda metade da década de 1950, diante do avanço da industrialização pesada e da consequente intensificação da concentração industrial no Sudeste, Furtado elaborou uma proposta para o desenvolvimento da região Nordeste, da qual fazia parte a criação da Superintendência do Desenvolvimento do Nordeste (Sudene).

Em face da consciência do problema regional brasileiro, Diniz (2009) ressalta o fato de que o governo brasileiro criou programas específicos de desenvolvimento regional, tais como a Sudene, a Superintendência do Desenvolvimento da Amazônia (Sudam) e a Zona Franca de Manaus (ZFM). O maior crescimento industrial do interior paulista e das demais macrorregiões só foi observado a partir da década de 1970, fruto dos efeitos dos programas de estímulo ao crescimento paulista e de políticas públicas que induziram investimentos nas regiões Nordeste, Norte, Sul e Centro-Oeste. Na década de 1970, houve, portanto, a combinação de dois processos: i) crescimento econômico (estimulado principalmente pelos investimentos do Milagre Econômico e do II Plano Nacional de Desenvolvimento) e ii) desconcentração regional da indústria, à medida que a taxa de crescimento do estado de São Paulo era menor que a das demais regiões, levando a uma participação maior destas na atividade produtiva nacional. Esse processo de forma alguma reverteu o caráter concentrador da produção nacional, pois São Paulo continuou a concentrar mais de 50\% do produto nacional em 1980.

A partir da década de 1980, segundo Cano (2011), surgiram novos desafios para o estudo da questão regional do Brasil em geral e para a dinâmica regional da indústria em particular. A crise da dívida externa, a crise fiscal e financeira do Estado brasileiro, a hiperinflação, entre outros fatores, levaram a uma crise do setor produtivo, com estagnação do processo de substituição de importações, o que resultou no rompimento do processo de industrialização que ganhara dinamismo a partir de 1930. A essas questões somam-se a reforma financeira, a abertura comercial e as privatizações, que vão modificar a dinâmica da indústria nacional e, consequentemente, terão rebatimentos espaciais significativos. A desconcentração regional terá continuidade, mas em um contexto em que a crise impactará de forma mais intensa a região mais industrializada e dinâmica. Cano (2011, p. 33) destaca que as mudanças econômicas "impactaram sobre as estruturas sociais e políticas, e causaram importantes alterações no processo de integração e desenvolvimento regional e no próprio processo de urbanização”.

Ao longo dos anos 1990, observou-se o total esvaziamento das políticas públicas e de instrumentos voltados para o desenvolvimento regional, à medida que ações descentralizadas de atração de investimentos vão se tornando frequentes, 
generalizando incentivos fiscais desencadeados pela guerra fiscal praticada por unidades da federação e municípios (CANO, 2011). Em meados da primeira década dos anos 2000, houve a tentativa de retomar a implementação de políticas de desenvolvimento regional por intermédio da Política Nacional de Desenvolvimento Regional (PNDR). No mesmo período, outras políticas, que não tinham o recorte regional, contribuíram para que novos dinamismos fossem criados no interior do país, a saber: ampliação das políticas sociais pelo Bolsa Família, investimentos em infraestrutura por meio do Plano de Aceleração do Crescimento (PAC), políticas de estímulo à agricultura familiar e desenvolvimento territorial e investimentos para a exploração de petróleo.

Ainda que durante as décadas de 1970 e 2000 tenha havido queda gradativa na participação do Sudeste no PIB industrial do país e que, por outro lado, as demais quatro regiões brasileiras tenham elevado sua participação na produção industrial, o movimento espacial que salta aos olhos é a dispersão intrarregional, no âmbito do Sul-Sudeste. Nesse sentido, pode-se falar em um fenômeno de "desconcentração concentrada" (AZZONI, 1986) ou de um "desenvolvimento poligonal" (DINIZ, 1993; CAIADO, 2002). Góis-Sobrinho (2014, p. 5) apresenta dados que confirmam essa tese:

\footnotetext{
A região Sul-Sudeste concentrou $76 \%$ do VAB da indústria em 2010, que se encontrou principalmente dentro e nos vértices do denominado Polígono Industrial, delimitado pelos municípios de Belo Horizonte (MG), Uberlândia (MG), Maringá/Londrina (PR), Porto Alegre (RS), Florianópolis (SC) e São José dos Campos (SP).
}

Ainda em relação ao tema da concentração espacial da indústria de transformação do país, Cruz e Santos (2009) afirmam que se localizam na região Sudeste, especialmente no estado de São Paulo, as microrregiões que mais padeceram com a perda de emprego industrial. Não obstante esse fato, os autores ressaltam que as regiões que continham uma base industrial relevante, por exemplo, no interior paulista, lograram elevar sua participação em indústrias de maior conteúdo tecnológico. Eles também argumentam que a explicação para esse fenômeno reside no fato de que tais indústrias não buscam incentivos fiscais, e sim os benefícios oriundos das economias de aglomeração, decorrentes em grande medida dos chamados transbordamentos de conhecimento (CRUZ; SANTOS, 2009). Nesse ponto, cabe salientar as contribuições de Benko (1999) para o comportamento de localização das empresas de alta tecnologia. Segundo o autor, esse comportamento está largamente condicionado por fatores como: i) presença de universidades e centros de pesquisa de excelência; ii) infraestrutura de transporte; iii) economias 
de aglomeração. No que se refere ao primeiro item, localizar-se nas proximidades dessas instituições permite às empresas se beneficiarem da oferta de mão de obra de alta qualidade, além de se envolverem em parcerias científicas e industriais. Em relação ao segundo item, os atrativos são as autovias de qualidade e o acesso rápido e fácil das pessoas às pontes aéreas.

Por fim, no tocante às economias de aglomeração, os principais pressupostos dessa teoria são os seguintes:

- As economias urbanas (geralmente presentes em grandes metrópoles) favorecem a constituição de redes de informação.

- As atividades de Pesquisa e Desenvolvimento (P\&D) estão, em grande medida, condicionadas pelas economias de aglomeração.

- O número elevado de empresas em um espaço reduz, proporcionalmente, os custos fixos ligados à infraestrutura.

- Esses elementos, conjuntamente, são responsáveis pela atração de novas empresas para a região considerada (BENKO, 1999).

As economias de aglomeração, na ausência de políticas governamentais que estimulem pesquisas e investimentos em infraestrutura de forma desconcentrada, podem reforçar a concentração das indústrias de intensidade tecnológica mais elevada, assim como os dispêndios inovativos em dada região. Cano (2011), Diniz (2019) e Diniz e Mendes (2021) mostram como os setores mais dinâmicos e de maior conteúdo tecnológico têm privilegiado as regiões de industrialização mais consolidada, notadamente no entorno das regiões metropolitanas das regiões Sudeste e Sul, ainda que espaços novos tenham se estabelecido. Por outro lado, novas áreas industriais ligadas a segmentos tradicionais têm se consolidado em áreas de menor tradição na industrialização, como a expansão das atividades industriais nas metrópoles nordestinas de Salvador, Recife e Fortaleza, e ainda o crescimento de atividades industriais conectadas ao agronegócio e à exploração de recursos naturais, características de novos espaços nas regiões Norte e Centro-Oeste (CANO, 2011).

Em relação a esses novos espaços, Diniz (2019) assinala que o processo de desconcentração industrial, mesmo arrefecido depois de 1980, teve continuidade nas duas últimas décadas, em que significativas “alterações macroespaciais” passaram a ocorrer: expansão das fronteiras agropecuária e mineral; efeitos de políticas sociais e de transferência de renda; impactos da política de educação e saúde; investimentos em infraestrutura; e um pacote de investimentos industriais apoiados pelo governo federal. Em conjunto, essas alterações estimularam a desconcentração industrial e a interiorização de atividades produtivas mais tradicionais.

Nas últimas décadas, os estudos sobre a configuração regional da indústria de transformação no Brasil encontram novos desafios em virtude do processo de 
perda de participação da indústria de transformação no PIB. Em relação a esse problema, Clark (1957) afirma que, à medida que um país vai alcançando estágios mais avançados de desenvolvimento, diminui o nível de elasticidade-renda da demanda para produtos industrializados, o que explicaria os ganhos relativos da participação do setor de serviços na renda e emprego totais, em detrimento da perda relativa do setor industrial. O estudo realizado por Rowthorn (1997) corrobora a tese de Clark (1957), ao demonstrar que o processo de desindustrialização dos países desenvolvidos já estava em curso a partir das décadas de 1960 e 1970. Cabe enfatizar que o processo de desindustrialização não necessariamente deve ser classificado como negativo, uma vez que a queda na participação da indústria no emprego e no valor adicionado (que configurariam a desindustrialização) pode estar associada a uma transferência para o exterior das atividades manufatureiras mais intensivas em trabalho e/ou com menor valor adicionado. Nesses casos, a desindustrialização estaria acompanhada do aumento na produção de bens industrializados intensivos em trabalho qualificado, ligados a setores de alto conteúdo tecnológico. Assim, esse padrão de desenvolvimento gera redução do emprego industrial, em termos relativos.

Entretanto, o processo de desindustrialização tem ocorrido também em países mais pobres, que ainda não consolidaram os impactos positivos da industrialização (TREGENNA, 2009; 2016). Segundo Palma (2005), o fenômeno da "desindustrialização precoce” tem se efetivado com frequência no âmbito da América Latina. Nesses países, a desindustrialização assume um perfil diferente daquele observado nas economias desenvolvidas, pois a expansão relativa se manifesta em segmentos econômicos de menor valor agregado, como agricultura e mineração, o que pode limitar seriamente o crescimento econômico e o catching-up.

A identificação de um processo de desindustrialização na economia brasileira tornou-se objeto de debate. Nesse contexto, a busca por identificar, mensurar e analisar esse processo transformou-se no foco de vários trabalhos, como os de Oreiro e Feijó (2010) e Bresser-Pereira e Marconi (2010). Herrendorf, Rogerson e Valentinyi (2014), ao caracterizarem o processo de desindustrialização, argumentam que tal fenômeno ocorre quando a indústria começa a perder participação no PIB numa etapa intermediária do desenvolvimento. Rodrik (2016) estima que nos países desenvolvidos esse fenômeno ocorre quando a renda per capita alcança o patamar de US\$ 20 mil em paridade do poder de compra (PPC) de 2016. De acordo com Morceiro e Guilhoto (2019), o Brasil dá início ao seu processo de desindustrialização já em 1981, quando sua renda per capita era de US\$10,8 mil (em PPC de 2016), portanto, em um patamar inferior àquele estimado por Rodrik (2016). Nesse sentido, pode-se classificar a desindustrialização brasileira como prematura, visto que limita o potencial de crescimento da economia do país. 
Furtado (1992) já alertava para os efeitos que a transnacionalização teria sobre um país ainda em formação, sobretudo no tocante à articulação de suas distintas regiões. Para o autor, a crise do processo de industrialização, aliada a uma transnacionalização maior das estruturas produtivas, reduziria a importância do mercado interno enquanto motor de crescimento em contrapartida a uma ampliação da integração aos mercados internacionais. Esse processo levaria ao enfraquecimento dos vínculos de solidariedade entre as distintas regiões, a tensões inter-regionais, a bolsões de miséria e ao enfraquecimento de um projeto nacional.

Dentro de uma perspectiva analítica baseada nas especificidades do processo de industrialização brasileira, em função de seu caráter subdesenvolvido e das assimetrias na difusão do progresso técnico que levaram o Brasil a um considerável atraso tecnológico, Sampaio (2017, p. 380) considera que a desindustrialização

[...] pode ser compreendida como a redução do grau de industrialização, com perda da diversificação produtiva, quebra de elos de cadeias produtivas e diminuição do papel da locomotiva paulista em determinado tempo histórico (pós-1980). A desindustrialização é nacional, porém com efeitos regionais diferenciados, dada a própria natureza da industrialização brasileira: desigual, heterogênea, dependente e periférica.

Nesse sentido, para o autor, o processo de desindustrialização aponta para modificações profundas na dinâmica regional, urbana e migratória, ampliando as heterogeneidades estruturais, das quais fazem parte as desigualdades regionais que marcaram o processo de industrialização no Brasil. Argumenta-se neste artigo que, para uma compreensão correta do desenvolvimento regional da indústria brasileira na atualidade, é fundamental considerar as seguintes dimensões: i) os descaminhos da industrialização por substituição de importações; ii) a concentração da indústria no Sudeste e; iii) a desindustrialização precoce. Essas três dimensões precisam ser analisadas dentro das especificidades do subdesenvolvimento brasileiro. Com base no alicerce teórico aqui construído, a finalidade das duas próximas seções será analisar as tendências recentes (entre as décadas de 2000 e 2010) da indústria do país, tendo como mote a questão regional.

\section{Tendências recentes do desenvolvimento regional no Brasil}

A análise das estruturas produtivas regionais mediante a composição setorial do VAB evidencia que as tendências de perda de participação da indústria de transformação brasileira se confirmam regionalmente para o período compreendido entre os anos de 2002 e 2017. Acompanhando a tendência nacional, observa-se na Tabela 1 que todas as regiões apresentaram crescimento relativo do setor de 
serviços no VAB. O setor agropecuário, por sua vez, experimentou peso relativo superior à média nacional nas regiões Norte, Centro-Oeste, Sul e Nordeste. Por outro lado, nas regiões Norte e Centro-Oeste, cujas estruturas agropecuárias têm expressiva ligação com as atividades de exportação, observa-se uma tendência de crescimento da participação relativa desse setor a partir de 2005.

\begin{tabular}{|c|c|c|c|c|c|c|c|c|c|c|}
\hline & \multicolumn{5}{|c|}{ Brasil } & \multicolumn{5}{|c|}{ Norte } \\
\hline Ano & Agro. & $\begin{array}{l}\text { Ind. } \\
\text { total }\end{array}$ & $\begin{array}{c}\text { Ind. } \\
\text { extrat. }\end{array}$ & $\begin{array}{c}\text { Ind. } \\
\text { transf. }\end{array}$ & Serviços & Agro. & $\begin{array}{l}\text { Ind. } \\
\text { total }\end{array}$ & $\begin{array}{c}\text { Ind. } \\
\text { extrat. }\end{array}$ & $\begin{array}{c}\text { Ind. } \\
\text { transf. }\end{array}$ & Serviços \\
\hline 2002 & 6,4 & 26,4 & 2,0 & 14,5 & 67,2 & 10,4 & 27,6 & 3,1 & 14,1 & 62,0 \\
\hline 2007 & 5,2 & 27,1 & 3,0 & 16,6 & 67,7 & 7,9 & 27,4 & 3,0 & 15,2 & 64,7 \\
\hline 2012 & 4,9 & 26,0 & 4,5 & 12,6 & 69,1 & 9,4 & 29,5 & 9,6 & 9,8 & 61,2 \\
\hline \multirow[t]{2}{*}{2017} & 5,3 & 21,1 & 1,6 & 12,4 & 73,5 & 10,5 & 26,2 & 6,4 & 9,6 & 63,3 \\
\hline & \multicolumn{5}{|c|}{ Nordeste } & \multicolumn{5}{|c|}{ Sudeste } \\
\hline Ano & Agro. & $\begin{array}{l}\text { Ind. } \\
\text { total }\end{array}$ & $\begin{array}{c}\text { Ind. } \\
\text { extrat. }\end{array}$ & $\begin{array}{c}\text { Ind. } \\
\text { transf. }\end{array}$ & Serviços & Agro. & $\begin{array}{l}\text { Ind. } \\
\text { total }\end{array}$ & $\begin{array}{c}\text { Ind. } \\
\text { extrat. }\end{array}$ & $\begin{array}{l}\text { Ind. } \\
\text { transf. }\end{array}$ & Serviços \\
\hline 2002 & 10,0 & 23,0 & 1,9 & 9,7 & 67,1 & 3,1 & 27,9 & 2,7 & 15,6 & 69,0 \\
\hline 2007 & 8,1 & 22,0 & 2,6 & 10,5 & 69,9 & 2,8 & 29,5 & 4,2 & 18,4 & 67,7 \\
\hline 2012 & 6,2 & 21,7 & 2,7 & 7,6 & 72,1 & 2,4 & 27,7 & 6,4 & 13,4 & 69,8 \\
\hline \multirow[t]{2}{*}{2017} & 6,6 & 18,9 & 0,5 & 9,6 & 74,5 & 2,5 & 21,5 & 2,1 & 13,2 & 76,1 \\
\hline & \multicolumn{5}{|c|}{ Sul } & \multicolumn{5}{|c|}{ Centro-Oeste } \\
\hline Ano & Agro. & $\begin{array}{l}\text { Ind. } \\
\text { total }\end{array}$ & $\begin{array}{c}\text { Ind. } \\
\text { extrat. }\end{array}$ & $\begin{array}{c}\text { Ind. } \\
\text { transf. }\end{array}$ & Serviços & Agro. & $\begin{array}{l}\text { Ind. } \\
\text { total }\end{array}$ & $\begin{array}{c}\text { Ind. } \\
\text { extrat. }\end{array}$ & $\begin{array}{l}\text { Ind. } \\
\text { transf. }\end{array}$ & Serviços \\
\hline 2002 & 10,8 & 29,1 & 0,2 & 19,0 & 60,1 & 11,5 & 16,3 & 0,4 & 6,5 & 72,2 \\
\hline 2007 & 8,6 & 28,8 & 0,2 & 20,5 & 62,6 & 8,3 & 16,1 & 0,6 & 7,7 & 75,7 \\
\hline 2012 & 7,3 & 28,1 & 0,2 & 18,1 & 64,6 & 10,8 & 16,8 & 0,6 & 7,4 & 72,4 \\
\hline 2017 & 8,5 & 24,6 & 0,2 & 17,0 & 66,9 & 9,9 & 13,9 & 0,3 & 6,9 & 76,2 \\
\hline
\end{tabular}

Tabela 1. Participação (\%) das atividades econômicas no (VAB), Brasil e macrorregiões brasileiras, em anos selecionados

Fonte: Contas regionais do Brasil (IBGE), vários anos.

Na região Norte, a participação relativa do setor industrial caiu 1,4 ponto percentual no VAB total regional, ao passo que a indústria de transformação caiu 4,5 pontos percentuais entre 2002 e 2017. A redução da importância relativa desse tipo de indústria na região em foco se deve aos efeitos da perda de dinamismo da economia nacional sobre a produção industrial do Polo Industrial de Manaus (PIM), com a predominância da indústria eletrônica e de motocicletas, que sofreram queda expressiva de demanda no contexto de crise. A partir de 2012, alguns segmentos industriais instalados no PIM começaram a registrar queda da produção, o que se agravou em 2015. A Tabela 1 evidencia os efeitos sobre a participação relativa da indústria de transformação no VAB da região. 
A dinâmica da indústria extrativa arrefeceu a queda relativa da indústria na estrutura produtiva regional. Encontram-se na região Norte áreas importantes de extração mineral, com a presença de grandes empresas, como é o caso da Vale, responsável pela exportação da maior parte do minério de ferro explorado na região. Há ali eixos relevantes de integração ao mercado interno por intermédio, sobretudo, do comércio de produtos provenientes do PIM, da agropecuária e da extração vegetal. Por outro lado, essa dinâmica estabelece laços com o exterior em decorrência da exportação de agropecuários, de produtos industrializados e, notadamente, de produtos oriundos da extrativa mineral. A ampliação da importância relativa da indústria extrativa na região Norte esteve relacionada à sua articulação aos fluxos de comércio internacional, em especial à expansão das exportações de minérios de ferro pelo estado do Pará, principal unidade da federação ofertante desse produto no mercado internacional. A dinâmica desse setor guarda relação direta com a dinâmica da demanda internacional, tendo sido positivamente influenciada pelo boom de commodities.

A região Nordeste, apesar de abrigar polos significativos de fruticultura irrigada no semiárido da Bahia, do Ceará, do Rio Grande do Norte e de Pernambuco, ao lado da expansão da soja para partes dos estados do Maranhão, do Piauí e da Bahia, apresentou queda expressiva de participação relativa do setor agropecuário.

No Nordeste, após um período de crescimento entre 2002 e 2009, a partir de 2010 a indústria de transformação começou a diminuir sua participação na estrutura produtiva da região, recuperando parte da participação relativa no VAB nos anos de 2015 e 2017. Vale lembrar que as políticas de atração de investimento (guerra fiscal) praticadas pelos estados nordestinos no final dos anos 1990 e na primeira década dos anos 2000 influenciaram a tomada de decisões de investimentos principalmente de segmentos industriais intensivos em mão de obra, acima de tudo calçados. As políticas de transferências de renda, investimentos do PAC, políticas de combate aos efeitos da seca, entre outras, podem explicar a ampliação da participação da indústria de transformação no VAB da região até 2009.

A região Centro-Oeste apresentou ligeira ampliação do peso relativo da indústria de transformação na sua estrutura produtiva entre 2002 e 2017 em virtude da expansão da agroindústria, notadamente a indústria de alimentos, bastante articulada à produção agropecuária. Por outro lado, houve ampliação de ramos mais sofisticados, tais como farmacêutica e automotivo, concentrados em municípios do estado de Goiás. É essencial destacar dois fatores explicativos para o aumento da importância relativa da indústria de transformação na região Centro-Oeste: i) a ampliação da produção agropecuária (sobretudo bovinos, milho e soja), em grande medida para exportação, provocou efeitos dinâmicos sobre setores como 
processamento de alimentos, frigoríficos, beneficiamento de sementes; além disso, ii) os três estados da região têm conseguido atrair investimentos industriais resultantes de incentivos fiscais.

A região Sudeste, que concentra a maior parte da produção nacional, apresentou queda de 6,4 p.p. de participação da indústria no VAB entre 2002 e 2017. A indústria de transformação teve sua participação na estrutura produtiva reduzida em 2,4 p.p. Seguindo a tendência da região Sudeste, na região Sul, que concentra mais de $20 \%$ da produção industrial nacional, a participação da indústria de transformação no VAB regional sofreu queda de 2,0 p.p.

Podemos estabelecer a seguinte periodização com base na Tabela 1:

- 2002-2008: queda menos acentuada da participação da indústria de transformação sobre o VAB para todas as macrorregiões brasileiras;

- de 2008 em diante: queda mais acentuada da participação da indústria de transformação sobre o VAB para as macrorregiões, exceto para a região Centro-Oeste.

Essas informações sugerem que a dinâmica de crescimento do país no período de 2004 a 2008, proveniente do dinamismo das atividades exportadoras, do fortalecimento do mercado interno e de estímulos ao investimento, em vez de evitar a desindustrialização nas macrorregiões brasileiras, a arrefeceu. Por outro lado, após a crise do subprime, as mudanças na demanda internacional, em conjunção com uma sucessão de eventos que levam a uma mudança de política econômica e do ritmo de crescimento do país, intensificam a queda da participação da indústria de transformação no VAB.

Dentro desse contexto mais geral de perda de participação relativa da indústria de transformação nas estruturas produtivas regionais, alguns indicadores mostram a continuidade da desconcentração regional da indústria brasileira. A Tabela 2 evidencia a participação das cinco macrorregiões no VAB total e no VAB da indústria de transformação. Percebe-se que a desconcentração da indústria de transformação é mais intensa que a descontração do conjunto das atividades econômicas.

Entre os anos de 2002 e 2017, as regiões Norte, Nordeste e Centro-Oeste apresentaram um processo contínuo de ampliação na participação no VAB nacional. A região Sul teve um ganho de participação menos expressivo, enquanto a região Sudeste sofreu queda de participação de 4,4 p.p. no VAB nacional. Esses dados tornam clara a continuidade do processo de desconcentração do VAB total a partir da região Sudeste. 


\begin{tabular}{|c|c|c|c|c|c|c|c|}
\hline \multicolumn{2}{|c|}{ Regiōes } & 2002 & 2005 & 2010 & 2015 & 2017 & $\begin{array}{c}\text { Variação } \\
\text { 2002-2017 }\end{array}$ \\
\hline \multirow{2}{*}{ Norte } & Total & 4,8 & 5,1 & 5,5 & 5,5 & 5,8 & 1,0 \\
\hline & Ind. transformação & 4,7 & 4,7 & 4,7 & 4,6 & 4,5 & $-0,2$ \\
\hline \multirow{2}{*}{ Nordeste } & Total & 13,5 & 13,4 & 13,9 & 14,5 & 14,8 & 1,4 \\
\hline & Ind. transformação & 9,0 & 8,7 & 9,0 & 10,7 & 11,4 & 2,4 \\
\hline \multirow{2}{*}{ Sudeste } & Total & 56,5 & 56,7 & 55,3 & 53,2 & 52,0 & $-4,4$ \\
\hline & Ind. transformação & 60,8 & 61,9 & 60,2 & 55,5 & 55,1 & $-5,7$ \\
\hline \multirow{2}{*}{ Sul } & Total & 16,4 & 16,0 & 16,0 & 16,9 & 17,1 & 0,7 \\
\hline & Ind. transformação & 21,5 & 20,6 & 21,1 & 23,4 & 23,3 & 1,8 \\
\hline \multirow{2}{*}{ Centro-Oeste } & Total & 8,9 & 8,9 & 9,3 & 9,9 & 10,3 & 1,5 \\
\hline & Ind. transformação & 4,0 & $-4,1$ & 5,1 & 5,8 & 5,8 & 1,8 \\
\hline
\end{tabular}

Tabela 2. Participação (\%) das atividades econômicas no (VAB), Brasil e macrorregiões brasileiras, em anos selecionados

Fonte: Contas regionais do Brasil (IBGE), vários anos.

Na região Norte, a expansão da indústria extrativa e do setor agropecuário explica a ampliação da participação regional no VAB nacional. Dessa forma, no que tange a essa região, percebe-se um impacto territorial importante, proveniente do boom de commodities e do perfil da inserção do Brasil nos fluxos de comércio internacional. Por outro lado, a participação da indústria de transformação da região Norte no VAB nacional vem apresentando tendência à queda, ao mesmo tempo que o setor sofre redução da sua participação relativa dentro da estrutura produtiva regional (Tabela 1).

Quanto à região Nordeste, houve aumento na participação nacional do VAB industrial da indústria de transformação. Essa tendência na região em foco é explicada pelos efeitos das políticas de transferência de renda, da ampliação do salário mínimo, de obras de infraestrutura, entre outras, que expandiram a capacidade de consumo e influenciaram decisões de investimento privados. Vale destacar, também, um conjunto de investimentos que foi coordenado pelo Estado, em estaleiros, na extração de petróleo e em obras do PAC.

A região Centro-Oeste também apresentou crescimento tanto na participação no VAB total como no industrial, explicado pela ampliação da importância da indústria de transformação regional. Trata-se de uma indústria bastante articulada ao setor agropecuário, mas a região tem atraído igualmente, no estado de Goiás, empresas do segmento automobilístico e farmacêutico. No caso da indústria de transformação, é perceptível a relevante articulação com o mercado da própria região e com o mercado nacional.

No que se refere ao VAB total e à indústria de transformação, as perdas de participação relativa da região Sudeste foram, respectivamente, de 4,4 p.p. e 
5,7 p.p. entre 2002 e 2017. De acordo com dados da Pesquisa Industrial Anual (PIA), no tocante à redução de participação relativa da região na indústria de transformação nacional, as quedas mais significativas no período que compreende os anos de 2008 a 2018 foram em alimentos (-12 p.p.), têxtil (-9 p.p.), papel e celulose (-20 p.p.), metalurgia (-25 p.p.), manutenção, reparação e instalação de máquinas e equipamentos $(-15,6)$, além de automóveis (-9 p.p.). Parte desses segmentos industriais foi direcionada para outras regiões, sob a influência, entre outros fatores, dos incentivos fiscais, como é o caso da produção de automóveis e papel celulose.

Os dados de participação regional no VAB setorial nacional revelam uma tendência de continuidade da reconfiguração regional da atividade produtiva, mas existem muitas limitações para que haja um desenvolvimento mais equilibrado, que supere a tendência concentradora da indústria brasileira. Apesar do processo de desconcentração descrito, a região Sudeste foi, em 2017, responsável por 52,0\% do Valor Adicionado Bruto Nacional e por 55,1\% do Valor Adicionado na Indústria de Transformação. Trata-se de um processo de desconcentração lento. Ademais, os segmentos mais intensivos em tecnologia e com maiores possibilidades de inovação estão concentrados naquela região, como será apresentado na seção 3 .

Outra dimensão frequentemente analisada em estudos no campo da economia industrial, e que pode contribuir para pesquisas que objetivam analisar a dinâmica regional brasileira, diz respeito à produtividade do trabalho. Do ponto de vista conceitual, pode-se afirmar que os indicadores de produtividade têm o intuito de mensurar "a eficiência com que a economia, ou os agentes econômicos, transforma insumos em produtos e serviços finais [...]" (DE NEGRI; CAVALCANTE, 2014, p. 29). De acordo com a literatura especializada, os países que apresentam as melhores performances econômicas no longo prazo são aqueles que logram aumentar a complexidade de sua estrutura produtiva e, concomitantemente, ampliar a produtividade em cada um dos setores produtivos (MONTEIRO NETO; SILVA; SEVERIAN, 2020).

Tal indicador corresponde ao quociente entre alguma medida de produto (como o VTI) e alguma medida de trabalho (por exemplo, o pessoal ocupado registrado na PIA-IBGE). Pode-se afirmar que esse indicador padece de algumas limitações, e a mais evidente delas consiste no fato de representar uma medida parcial de produtividade, tendo em vista que a produtividade do trabalho abarca apenas um recurso produtivo utilizado na produção (a mão de obra), sem levar em conta a intensidade ou a qualidade do capital empregado. Adicionalmente, esse indicador, sozinho, não nos permite aferir a qualidade do capital humano, ou, dito de outra forma, a capacitação e o grau de instrução da mão de obra (DE NEGRI; CAVALCANTE, 2014). 
A despeito das deficiências enxergadas no referido indicador, acredita-se que ele pode trazer algumas pistas interessantes acerca da dinâmica regional da indústria de transformação brasileira, evidenciando possíveis diferenças em termos dos perfis da indústria de transformação das cinco regiões brasileiras (por exemplo, maior intensidade em capital ou em trabalho) a serem confrontados com as análises contidas na literatura que se debruça sobre o tema. Nesse ensejo, a Tabela 3 tem a finalidade de apresentar dados sobre a evolução desse indicador na indústria de transformação no Brasil e nas cinco macrorregiões, em anos selecionados. Eles foram calculados com base na relação entre VTI e o Pessoal Ocupado.

\begin{tabular}{c|c|c|c|c|c|c}
\hline Anos selecionados & N & NE & C-O & SE & S & BR \\
\hline 2002 & - & 111 & 99 & 168 & 115 & 141 \\
\hline 2005 & - & 111 & 126 & 174 & 113 & 144 \\
\hline 2010 & 227 & 109 & 137 & 170 & 123 & 151 \\
\hline 2015 & 220 & 121 & 156 & 160 & 122 & 147 \\
\hline 2017 & 228 & 122 & 146 & 167 & 125 & 151 \\
\hline Taxa média anual & 0,06 & $0,63 \%$ & $2,62 \%$ & $0,04 \%$ & $0,56 \%$ & $0,46 \%$ \\
\hline
\end{tabular}

Tabela 3. Produtividade (regional e brasileira) por trabalhador (VTI/Pessoal Ocupado em R\$ mil* por trabalhador) na indústria de transformação (anos selecionados)

Nota: *Valores monetários corrigidos pelo IPCA (2018 = 100).

Fonte: PIA/IBGE, vários anos.

Em relação à Tabela 3, é importante destacar inicialmente que não há dados disponíveis para a região Norte em 2002 em virtude das seguintes situações: i) valor inibido para não identificar o informante; e ii) zero absoluto, não resultante de um cálculo ou arredondamento. Essa situação ocorre também em anos mais recentes, mas não a ponto de causar viés nos dados. Nesse sentido, optamos por excluir aqueles relativos a 2002 e 2005 referentes à região Norte, para não distorcer nossa análise sobre o perfil da produtividade da mão de obra da indústria de transformação dessa região.

Os dados apresentados na Tabela 3 revelam que a região Norte do país ocupa o topo da lista, com certa folga em relação às demais. Em primeiro lugar, é possível compreender esse fenômeno como resultado da presença de empresas mais dinâmicas do ponto de vista tecnológico (atuando em segmentos industriais como fabricação de equipamentos de informática e produtos eletrônicos e ópticos) no PIM, o que tende a elevar o nível médio de produtividade. No entanto, dois pontos devem ser aqui considerados: i) a região Norte apresenta participação reduzida na indústria de transformação brasileira (inferior a 10\%, de acordo com os dados da Tabela 1); e ii) a incapacidade observada em indústrias maquiladoras, como é o 
caso do PIM, de criar elos com a indústria do país e no que tange à endogeinização de atividades tecnológicas mais nobres (como a concepção de projetos/designs e o desenvolvimento e a fabricação de componentes críticos).

Por fim, cabe o registro da taxa de crescimento anual relativamente modesta da produtividade da mão de obra em relação a quatro regiões específicas: Norte $(0,06 \%)$, Nordeste $(0,63 \%)$, Centro-Oeste $(2,62 \%)$ e Sul $(0,56)$, convergindo com a taxa de crescimento igualmente diminuta registrada pelo Brasil $(0,46)$. O Sudeste é o caso extremo: a taxa de crescimento anual da produtividade da mão de obra foi negativa:-0,04. Os dados apresentados na Tabela 2 confirmam o pessimismo presente no estudo de Monteiro Neto, Silva e Severian, (2020) a respeito da produtividade da mão de obra na indústria brasileira, segundo os quais se evidencia uma dificuldade para o crescimento desse indicador nos vários ramos industriais.

No período em análise, para a indústria de transformação especificamente, podemos destacar algumas tendências:

- Embora com alguns investimentos mais desconcentrados, ramos industriais ligados à fabricação de automóveis, produção de máquinas e equipamentos apresentam grande concentração nas regiões Sul e Sudeste.

- Outras partes do território nacional foram bastante impactadas pela dinâmica de exportação de commodities. Na região Centro-Oeste, por exemplo, houve expansão significativa da produção de alimentos nos estados de Mato Grosso e Mato Grosso do Sul. Esse processo esteve relacionado à expansão da fronteira agropecuária, influenciando processos de urbanização e impactando o sistema produtivo.

- Parte da região Nordeste foi igualmente impactada pelo processo descrito acima. Nessa região, é possível identificar o crescimento de segmentos industriais ligados à produção de bens de consumo não duráveis, mas também houve ampliação dos investimentos em refino de petróleo até 2015. Muitos desses investimentos começaram a ser abandonados nos anos recentes. A região Norte foi bastante impactada pelo boom de commodities, que dinamizou parte do território regional, levando a certa diversificação produtiva. No entanto, por outro lado, a produção industrial associada a ramos mais sofisticados, concentrados no PIM, sofreu impactos da crise.

\section{Dinâmica industrial nas regiões brasileiras à luz de indicadores tecnológicos e de inovação}

No bojo da análise empreendida neste artigo sobre a dinâmica regional da indústria de transformação brasileira, o objetivo desta seção é acrescentar novos elementos a essa discussão. Mais precisamente, o foco aqui será trazer à tona dados 
que permitam construir um retrato da evolução recente - de 2000 em diante - da indústria de transformação no âmbito das cinco macrorregiões do Brasil, levando em conta fatores tecnológicos e inovativos. Assim, pretende-se elucidar em que medida a questão da (des)concentração desse setor da economia brasileira se manifesta tendo como pano de fundo tais fatores.

Para tanto, é apresentado um conjunto de indicadores tecnológicos e inovativos. Dentro dessa perspectiva, cumpre ressaltar a proeminência da classificação de intensidade tecnológica (P\&D/Receita Líquida de Vendas) da OCDE, a qual subdivide as indústrias em alta, média-alta, média-baixa e baixa tecnologia (HATZICHRONOGLOU, 1997). Essa classificação é amplamente utilizada em estudos comparativos entre empresas, setores e países. É válido ressaltar que, apesar de sua frequente utilização em estudos na área de CT\&I, a tipologia da OCDE não está isenta de críticas. Algumas delas são a importância excessiva atribuída à atividade de P\&D em detrimento de outras atividades inovativas, assim como o fato de desconsiderar que a P\&D e a inovação desenvolvidas em um segmento podem beneficiar outras indústrias (HIRSCH-KREINSEN et al., 2003; VON TUNZELMANN; ACHA, 2005; RIBEIRO et al., 2019).

Em que pese a pertinência dessas críticas, acreditamos que os problemas que a classificação da OCDE carrega não invalidam sua utilização para avaliar e comparar o perfil tecnológico da indústria de transformação nas cinco macrorregiões brasileiras. Além disso, para enriquecer a análise e evitar um eventual viés existente em uma investigação apoiada somente na tipologia da OCDE, nesta seção são introduzidos outros indicadores, quais sejam: i) participação relativa das regiões brasileiras nos gastos em inovação realizados pelas empresas industriais do país; ii) participação relativa das regiões brasileiras nas inovações em produto e processo realizadas pelas empresas que compõem a indústria de transformação do país.

A Tabela 4 resulta do esforço para associar os segmentos da indústria de transformação brasileira, desagregados por divisões (ou seja, a dois dígitos da Classificação Nacional de Atividades Econômicas - CNAE 2.0), à tipologia da OCDE. Cabe destacar que, como dados regionais para receita líquida de vendas e P\&D não são disponibilizados na Pesquisa de Inovação (PINTEC), realizada pelo IBGE, considerando o nível de desagregação que está sendo utilizado neste estudo, foi adotado como proxy o VTI dos diferentes segmentos industriais, agrupados dentro das quatro categorias dessa tipologia. 


\begin{tabular}{c|c|c|c|c|c|c|c|c|c|c|c|c}
\hline & \multicolumn{4}{|c}{ Baixa } & \multicolumn{3}{c}{ Média-baixa } & \multicolumn{3}{c}{ Média-alta } & \multicolumn{3}{c}{ Alta } \\
\hline Regiões & $\mathbf{2 0 0 8}$ & $\mathbf{2 0 1 8}$ & Var. & $\mathbf{2 0 0 8}$ & $\mathbf{2 0 1 8}$ & Var. & $\mathbf{2 0 0 8}$ & $\mathbf{2 0 1 8}$ & Var. & $\mathbf{2 0 0 8}$ & $\mathbf{2 0 1 8}$ & Var. \\
\hline N & 5,2 & 4,2 & -1 & 2,6 & 2,5 & $-0,1$ & 3,5 & 2,8 & $-0,7$ & 19,1 & 18,3 & $-0,8$ \\
\hline NE & 11,7 & 11,5 & $-0,2$ & 11,1 & 11,4 & 0,3 & 7,3 & 9,7 & 2,4 & 3,1 & 2,5 & $-0,6$ \\
\hline C-O & 8 & 10,5 & 2,5 & 2,3 & 4,8 & 2,5 & 1,5 & 1 & $-0,5$ & 1,9 & 2,8 & 0,9 \\
\hline SE & 47,2 & 43,2 & -4 & 69,2 & 66,4 & $-2,8$ & 67,1 & 62,7 & $-4,4$ & 66,5 & 70,2 & 3,7 \\
\hline S & 27,9 & 30,5 & 2,6 & 14,9 & 14,8 & $-0,1$ & 20,6 & 23,8 & 3,2 & 9,4 & 6,2 & $-3,2$ \\
\hline
\end{tabular}

Tabela 4. Participação relativa (\% em relação ao país) da indústria de transformação por macrorregião, de acordo com a intensidade tecnológica (2008 e 2018, e variação)*

Nota: Tabela elaborada com base nos dados extraídos da "Tabela 1849 - Dados gerais das unidades locais industriais de empresas industriais com 5 ou mais pessoas ocupadas, por Unidade da Federação, segundo as divisões de atividades (CNAE 2.0)".

Fonte: Adaptado de Cavalcante (2014) e PIA/IBGE (2008 e 2018).

Antes de procedermos à análise da Tabela 4, é relevante frisar que se optou por não incluir dados do começo da década de 2000 para compará-los com o período mais recente. Essa opção se deve às discrepâncias entre a CNAE 1.0 (que vigorou até 2007) e a CNAE 2.0. As diferenças repercutem sobre as divisões da indústria de transformação e, consequentemente, interferem na composição dos segmentos de baixa, média-baixa, média-alta e alta intensidade tecnológica, especialmente na formação dos dois últimos grupos. Portanto, utilizou-se somente a CNAE 2.0 para preservar a comparabilidade entre os dois períodos investigados.

Os dados presentes na Tabela 4 evidenciam o protagonismo do Sudeste na indústria de transformação brasileira, corroborando a tendência apontada nas duas seções anteriores do artigo. Cabe ressaltar o papel de relevo desempenhado pelas empresas industriais dessa região do país nos quatro grupos, tanto em 2008 como em 2018. Apesar de ter sofrido uma perda em seu peso relativo nas indústrias de baixa, média-baixa e média-alta tecnologia (de 4 p.p., 2,7 p.p. e de 4,4 p.p., respectivamente), nos três casos o peso relativo da região é bastante expressivo. Além disso, é digno de nota o aumento na participação relativa do Sudeste no grupo de alta tecnologia (de 3,8 p.p. - alcançando, neste caso, o patamar de 70\% em 2018). Resumidamente, os dados da Tabela 4 demonstram que, ainda que tenha sofrido queda em três dos quatro grupos que compõem a classificação da OCDE, a indústria do Sudeste continua a ter participação muito expressiva nos quatro grupos, sobretudo daqueles mais intensivos em tecnologia. O processo de desconcentração apresentado na seção anterior foi parcial, visto que o Sudeste, notadamente o estado de São Paulo, concentra a parte mais sofisticada da indústria de transformação do país.

Além do Sudeste, cumpre salientar o papel de destaque da indústria localizada na macrorregião Sul. Ela ocupa o segundo posto em três das quatro categorias 
identificadas na Tabela 4, tendência coerente com o fato de a região Sul do Brasil ser a segunda macrorregião mais industrializada, com produção industrial correspondente a $23 \%$ do Valor Agregado na indústria de transformação nacional (ver a seção 2 deste artigo). Com o aporte dos dados da Tabela 4, em relação à indústria de transformação dessa região, e reiterando que a classificação foi elaborada tendo como parâmetro os dados de VTI das regiões brasileiras, o resultado líquido foi, entre 2008 e 2015, de 2,5 (considerando em conjunto tanto as elevações quanto as quedas). Sobressai o aumento na participação, da ordem de 2,6 p.p., das indústrias do Sul no grupo formado pelas empresas com baixa intensidade tecnológica e pelas de média-alta intensidade tecnológica, de 3,2 p.p.

No que se refere à indústria de baixa intensidade tecnológica, a indústria de transformação da região Sul ampliou a participação nos segmentos produtores de alimentos, fumo, têxteis, vestuários, produtos de madeira, móveis, papel e celulose e de impressão e reprodução de gravações. Percebe-se que, em alguns segmentos, a expansão industrial guarda relação com sua base agropecuária e com produtos tradicionalmente produzidos na região. Ainda que ocupe a liderança nacional em segmentos industriais de baixa intensidade tecnológica (quais sejam, fabricação de produtos do fumo, fabricação de produtos de madeira e fabricação de móveis), a região Sul do Brasil também desempenha papel de destaque em segmentos como fabricação de máquinas, aparelhos e materiais elétricos, fabricação de máquinas e equipamentos, automóveis e outros veículos automotores, integrantes do grupo das indústrias de média-alta intensidade tecnológica.

Além disso, ao longo do período examinado é possível identificar, no caso dessas três indústrias, aumento do peso relativo do Sul: i) a fabricação de produtos alimentícios passou de 25,5\% para 27,5\%; ii) a fabricação de máquinas, aparelhos e materiais elétricos foi de $28 \%$ para $32,6 \%$; e iii) a fabricação de máquinas e equipamentos foi de $28,3 \%$ para $35,3 \%$.

O Nordeste ocupa a terceira posição no tocante à participação na indústria de transformação brasileira e, com base nos dados da Tabela 4, verifica-se participação mais expressiva dessa região nos segmentos de baixa e média-baixa intensidade tecnológica. Apesar de contar com uma parcela maior (no contexto nacional) entre os segmentos industriais de menor dinamismo tecnológico, como se registra na tabela apresentada, merece destaque o aumento de 2,5 p.p. da participação relativa das indústrias de média-alta intensidade tecnológica localizadas nessa região, entre 2008 e 2018. Nesse ponto, o peso relativo de dois segmentos industriais nordestinos deve ser salientado: i) a fabricação de produtos químicos (cerca de 16\%); e ii) a fabricação de outros equipamentos de transporte, exceto veículos automotores (o Nordeste alcançou participação relativa de 8,4\% em 2018, ante o patamar de 5,2\% em 2008). 
Quanto ao Norte e ao Centro-Oeste, tais regiões se apresentam como coadjuvantes (com participação relativa inferior a dois dígitos) na maior parte dos segmentos industriais brasileiros, entre as quatro categoriais analisadas na Tabela 4. As indústrias de alta tecnologia preponderam no parque industrial da região Norte, em virtude da localização do PIM, o que explica a elevada participação relativa das empresas industriais de alta tecnologia ali localizadas: 18,31\% em 2018. Ênfase deve ser dada à fabricação de equipamentos de informática, produtos eletrônicos e ópticos, segmento em que a região Norte ocupa o segundo lugar no ranking nacional, com participação relativa de 35,87\% em 2018, atrás apenas da região Sudeste (cujo peso relativo foi de $52,68 \%$ ).

Por fim, ainda que sua participação relativa na indústria de transformação brasileira seja pequena, entre 2008 e 2018 a região Centro-Oeste se elevou nos quatro grupos analisados na Tabela 4 (aumento de 6,13 p.p., considerando esses grupos conjuntamente). $\mathrm{O}$ aumento foi mais expressivo nas indústrias de baixa intensidade tecnológica, grupo em que ocupa a quarta posição no país, mas com uma diferença pequena diante dos estados do Sul e do Nordeste. No que diz respeito ao vetor de atração de empreendimentos industriais para o Centro-Oeste do país, é importante levar em conta a força da expansão da renda decorrente do crescimento da demanda mundial por commodities agrícolas (soja) nos estados de Goiás, Mato Grosso do Sul e Mato Grosso (MONTEIRO NETO; SILVA; SEVERIAN, 2020).

Os dados apresentados na Tabela 4 apontam para uma dispersão regional mais elevada na medida em que se passa das indústrias de mais alta intensidade tecnológica para aquelas cuja intensidade é menor. Prova disso é o fato de que a indústria da região Sudeste do país perdeu participação relativa tanto nas indústrias de baixa intensidade tecnológica como naquelas de média-baixa intensidade. Por outro lado, o protagonismo dessa região, que já era elevado no início do período abarcado pelo estudo em relação às indústrias de alta intensidade tecnológica (66,5\% em 2008), aumentou cerca de 4 p.p. até 2018, chegando a uma participação relativa de 70,2\%. O segmento industrial responsável pela fabricação de equipamentos de informática, assim como de produtos eletrônicos e ópticos, foi o principal responsável por essa elevação. Nesse segmento, a região Sudeste experimentou elevação de mais de 7 p.p. entre 2008 e 2018 (de 45,33\% para 52,68\% do total).

O objetivo da Tabela 5 é, ainda com base na tipologia de intensidade tecnológica, revelar a participação relativa dos quatro grupos da classificação da OCDE no contexto brasileiro e dentro de cada uma das cinco regiões. Vale relembrar: essa tipologia utiliza como parâmetro o VTI das divisões da indústria de transformação, localizadas nas cinco regiões do país. 


\begin{tabular}{|c|c|c|c|}
\hline & Grupos & 2008 & 2018 \\
\hline \multirow{7}{*}{ Regiões } & Grupos & 2008 & 2018 \\
\hline & Baixa & 30,95 & 37,74 \\
\hline & Média-baixa & 34,22 & 31,95 \\
\hline & Baixa + média-baixa & 65,17 & 69,69 \\
\hline & Média-alta & 29,12 & 24,84 \\
\hline & Alta & 5,71 & 5,47 \\
\hline & Média-alta + alta & 34,83 & 30,31 \\
\hline \multirow{6}{*}{ Norte } & Baixa & 35,11 & 38,89 \\
\hline & Média-baixa & 19,00 & 19,73 \\
\hline & Baixa + média-baixa & 54,11 & 58,62 \\
\hline & Média-alta & 22,30 & 17,00 \\
\hline & Alta & 23,58 & 24,38 \\
\hline & Média-alta + alta & 45,88 & 41,38 \\
\hline \multirow{6}{*}{ Nordeste } & Baixa & 37,22 & 41,25 \\
\hline & Média-baixa & 39,17 & 34,53 \\
\hline & Baixa + média-baixa & 76,39 & 75,78 \\
\hline & Média-alta & 21,78 & 22,94 \\
\hline & Alta & 1,83 & 1,27 \\
\hline & Média-alta + alta & 23,61 & 24,21 \\
\hline \multirow{6}{*}{ Centro-Oeste } & Baixa & 64,95 & 67,06 \\
\hline & Média-baixa & 20,45 & 25,95 \\
\hline & Baixa + média-baixa & 85,4 & 93,01 \\
\hline & Média-alta & 11,70 & 4,36 \\
\hline & Alta & 2,91 & 2,63 \\
\hline & Média-alta + alta & 14,61 & 6,99 \\
\hline \multirow{6}{*}{ Sudeste } & Baixa & 23,70 & 28,65 \\
\hline & Média-baixa & 38,43 & 37,28 \\
\hline & Baixa + média-baixa & 62,13 & 65,93 \\
\hline & Média-alta & 31,71 & 27,33 \\
\hline & Alta & 6,16 & 6,74 \\
\hline & Média-alta + alta & 37,87 & 34,07 \\
\hline \multirow{6}{*}{ Sul } & Baixa & 42,65 & 51,19 \\
\hline & Média-baixa & 25,13 & 21,06 \\
\hline & Baixa + média-baixa & 67,78 & 72,25 \\
\hline & Média-alta & 29,57 & 26,24 \\
\hline & Alta & 2,65 & 1,51 \\
\hline & Média-alta + alta & 32,22 & 27,75 \\
\hline
\end{tabular}

Tabela 5. Participação relativa (\%), por grupo tecnológico, no Brasil e nas macrorregiões (2008 e 2017) Fonte: Contas regionais do Brasil (IBGE), vários anos.

Os dados apresentados nessa Tabela 5 revelam que a indústria de transformação de quatro das cinco regiões brasileiras (Norte, Centro-Oeste, Sudeste e Sul) apresentou aumento na participação relativa das indústrias de baixa e média-baixa 
intensidade tecnológica. Dessa constatação, desdobra-se uma segunda: em tais regiões também houve queda na participação relativa das indústrias de média-alta e alta intensidade tecnológica. Mesmo nas regiões Norte e Sudeste, em que tradicionalmente as indústrias de média-alta + alta intensidade tecnológica possuem peso maior na comparação com as demais regiões do país, houve queda na participação relativa desse grupo para as regiões no período examinado. O mesmo fenômeno se observa em relação à indústria de transformação brasileira.

Essa tendência tem que ser vista como um alerta ao setor industrial do Brasil e das diferentes regiões, pois, além de sofrer queda de participação da indústria de transformação nas estruturas produtivas, como vimos na Tabela 1, há perda de sofisticação, em virtude da perda de peso relativo do conjunto de segmentos industriais classificados como indústria de média alta e alta intensidade tecnológica.

O Nordeste é a única exceção, pois o relativo do grupo média-alta + alta intensidade tecnológica cresceu de 23,61\% para 24,21\%, entre 2008 e 2018, dentro da própria indústria de transformação, com ampliação de participação dos segmentos de material elétrico, veículos automotores, outros equipamentos de transporte e produtos farmoquímicos e farmacêuticos. Todavia, três pontos devem ser aqui considerados: i) trata-se de um aumento pífio; ii) o peso relativo do grupo baixa + média-baixa intensidade tecnológica é extremamente elevado nessa região (cerca de 90\% em 2017); e iii) a região Nordeste apresenta participação reduzida na indústria de transformação brasileira (de aproximadamente 10\% do VAB desse setor da economia brasileira).

A Tabela 6 exibe dados acerca da participação das cinco regiões brasileiras no dispêndio industrial total em inovação, em 2000, 2003, 2005, 2008, 2011 e 2014 (coincidindo com as edições da Pintec). Vale destacar que o conceito de inovação utilizado pela Pintec/IBGE envolve: i) projeto industrial e outras preparações técnicas; ii) introdução das inovações tecnológicas no mercado; iii) treinamento; iv) aquisição de máquinas e equipamentos; v) aquisição de software; vi) aquisição de outros conhecimentos externos; vii) aquisição externa de P\&D; e viii) atividades internas de P\&D. Ao considerar essa miríade de possibilidades, a pesquisa do IBGE retira o peso excessivo imputado à $\mathrm{P} \& D$ pela classificação da OCDE.

O que chama atenção na Tabela 6 é a grande concentração do dispêndio industrial em inovação na região Sudeste. Ainda que tenha havido queda entre 2000 e 2014 (de $72 \%$ para $69 \%$ do total), tal participação continua muito expressiva. A região Sul vem logo atrás do Sudeste no que se refere aos dispêndios em inovação realizados pela indústria, em todos os anos contemplados pela Pintec, a despeito de uma ligeira queda, entre 2000 e 2014, de 3 p.p. É importante salientar o aumento na participação relativa do Nordeste e do Centro-Oeste ao longo do período analisado, 
de $4 \%$ para $8 \%$ e de $1 \%$ para $3 \%$, respectivamente. Por fim, quanto à região Norte, sua participação no total despendido pela indústria brasileira em atividades inovativas se manteve (4\%).

\begin{tabular}{l|c|c|c|c|c|c}
\hline Regiões & $\mathbf{2 0 0 0}$ & $\mathbf{2 0 0 3}$ & $\mathbf{2 0 0 5}$ & $\mathbf{2 0 0 8}$ & $\mathbf{2 0 1 1}$ & $\mathbf{2 0 1 4}$ \\
\hline Norte & 4 & 5 & 5 & 4 & 4 & 4 \\
\hline Nordeste & 4 & 7 & 7 & 5 & 4 & 8 \\
\hline Sudeste & 72 & 68 & 68 & 73 & 70 & 69 \\
\hline Sul & 19 & 19 & 19 & 15 & 16 & 16 \\
\hline Centro-Oeste & 1 & 1 & 1 & 3 & 5 & 3 \\
\hline
\end{tabular}

Tabela 6. Participação relativa (\%) das regiões brasileiras nos dispêndios inovativos da indústria de transformação

Fonte: Elaborada pelos autores baseados na Pintec (vários anos).

Embora a indústria de transformação do Sudeste venha perdendo participação, cerca de 70\% dos dispêndios inovativos estão concentrados nessa região um indicador que praticamente não sofreu alteração entre 2000 e 2014 (Tabela 6). A região Sudeste perde participação na indústria de transformação nacional em alguns segmentos classificados como baixa, média-baixa e média-alta intensidade tecnológica, mas ganha naqueles considerados de alta intensidade. Trata-se de uma desconcentração concentrada, à medida que as atividades industriais de média-alta intensidade tecnológica das regiões Sudeste e Sul correspondiam, em 2018, a 86,5\% dessas atividades industriais nacionais. No que concerne à alta intensidade tecnológica, as atividades dessas duas regiões correspondiam a 76,4\% no mesmo ano (Tabela 4).

\section{Interpretações de tendências e problematizações de resultados}

As tendências para a indústria brasileira observadas nas duas últimas décadas são de queda da participação da indústria de transformação no VAB e de redução da participação de indústrias de média-alta e alta intensidade tecnológica na estrutura da indústria, o que pode apontar para uma especialização regressiva da estrutura produtiva industrial nacional. Mesmo diante desse processo, a desconcentração regional da indústria tem continuidade, uma vez que a região Sudeste seguiu reduzindo sua participação na produção nacional (queda de 5,7 p.p. entre 2002 e 2017). Essa perda de participação relativa corresponde, na verdade, a perdas do estado de São Paulo; pode-se mesmo afirmar que o processo de descontração industrial se efetiva a partir desse estado. A despeito da perda relativa da participação do Sudeste, a indústria é altamente concentrada nessa região, notadamente em São Paulo, cuja produção industrial correspondia, em 2017, a 37\% da produção nacional. 
Foge do escopo deste artigo fazer uma análise pormenorizada das atividades produtivas das distintas regiões brasileiras, pois estamos trabalhando com um tema de ampla complexidade, com múltiplas determinações. Além disso, o período aqui analisado compreende momentos de expansão do crescimento e momentos de crise e estagnação econômica. Entre os fatores que influenciaram o processo de desconcentração, destacam-se: a dinâmica de crescimento da economia nacional (considerando a expansão e o esgotamento da capacidade de crescimento da economia); a dinâmica do mercado interno, considerando as políticas que impactaram a ampliação do consumo interno, seguida de um momento de crise com aumento do desemprego; a dinâmica das exportações, que causaram impactos significativos naqueles espaços produtores e exportadores de produtos agropecuários e da extrativa mineral.

O protagonismo do Sudeste diante da dinâmica tecnológica e inovativa da indústria brasileira pode ser explicado pela existência, na região, de universidades e centros de pesquisas de excelência, infraestrutura de transporte e economias de aglomeração. Na inexistência de uma política deliberada de desconcentração de atividades mais dinâmicas do ponto de vista tecnológico, há fortes indícios (teóricos e empíricos) que apontam para uma tendência de manutenção desse cenário. Defende-se aqui que, para lograr sucesso em uma empreitada de desconcentração das atividades de maior conteúdo tecnológico, seria necessário que as autoridades governamentais implementassem políticas públicas que vão além dos incentivos aos investimentos industriais. Uma política de desenvolvimento requer ações integradas de financiamento e estímulo a pesquisas e inovações, o fortalecimento das universidades e dos centros de pesquisa locais, assim como investimento em infraestrutura urbana, de transporte, entre outras medidas.

Outro fenômeno identificado neste artigo diz respeito ao aumento da participação relativa das indústrias de baixa e média-baixa intensidade tecnológica em praticamente todas as regiões brasileiras (inclusive no Sudeste). Tal fenômeno pode ser explicado pelo desprestígio da política de CT\&I na agenda do governo brasileiro (em razão do pequeno orçamento destinado a essa pasta e, ainda assim, contingenciamentos frequentes de recursos), pela falta de articulação entre os atores que compõem o Sistema Nacional de Inovação, pelo predomínio das empresas multinacionais nas indústrias de maior intensidade tecnológica (as quais tendem a realizar atividades como P\&D e design no país de origem) e pela reduzida competitividade do Brasil vis-à-vis outras economias emergentes (fazendo-nos perder oportunidades de adensamento tecnológico via cadeias globais de valor). 


\section{Considerações finais}

Diante do exposto neste artigo, é possível perceber alguns dos percalços no processo de industrialização do país que atravancaram o desenvolvimento subsequente do setor. Há traços que caracterizaram esse processo, enfatizados nos escritos cepalinos e furtadianos, tais como a baixa taxa de poupança e de investimentos privados, a diversificação da pauta de consumo da classe privilegiada, a concentração de renda, o predomínio das empresas multinacionais nas indústrias de bens de consumo duráveis, a dependência tecnológica e o baixo dinamismo das exportações industriais, que ainda se fazem presentes. Com base nesse pano de fundo, este artigo abordou o fenômeno da concentração espacial da produção industrial no Brasil.

Conforme ressaltado, a estruturação da produção nas diferentes frações do território foi resultado de heranças históricas, estruturas produtivas que foram se articulando à medida que se concretizavam a integração produtiva do espaço econômico nacional e a estruturação de uma divisão inter-regional do trabalho. Essa articulação se efetivou em um processo de industrialização periférico, marcado por heterogeneidades estruturais, das quais faz parte a diferenciação regional da renda e da produção.

O enfrentamento da questão regional brasileira e a superação das disparidades regionais requerem que a capacidade de crescimento da economia seja recuperada dentro de um modelo orientado para a redução das desigualdades sociais e da concentração da renda. Nesse sentido, dois eixos são fundamentais: i) o fortalecimento do mercado interno, para o qual é imprescindível a melhor distribuição de renda; ii) um esforço de agregação de valor dos produtos exportados, a fim de ampliar a articulação dessas atividades exportadoras a outras atividades produtivas com possibilidade de geração de emprego e renda. Ademais, há a necessidade de mapear e identificar as potencialidades e as especificidades das regiões, com vistas a formular políticas que levem em consideração as estruturas produtivas herdadas.

Por fim, cabe salientar que os dados apresentados neste artigo apontam para problemas que extrapolam a dimensão regional, quais sejam a desindustrialização precoce e a redução da presença dos segmentos de maior conteúdo tecnológico na indústria de transformação brasileira. Diante do exposto, defende-se que o país carece de uma política de reindustrialização. Ainda que nas duas últimas décadas as políticas industriais e tecnológicas tenham aparecido de maneira mais explícita na agenda do governo brasileiro (ver, por exemplo, Política Industrial, Tecnológica e de Comércio Exterior - PITCE, Plano de Desenvolvimento de Pessoas - PDP e Plano Brasil Maior), o conservadorismo da política macroeconômica representou um entrave de peso ao alcance de objetivos mais ambiciosos. 
Reivindica-se aqui um programa de reindustrialização que seja guiado pela tradição furtadiana; para isso, o Estado brasileiro precisa assumir o protagonismo desse processo, por meio de uma coordenação complexa de decisões, viável apenas com a implementação de políticas de planejamento, ou seja, de uma estratégia deliberada que condicione os processos econômicos no seu conjunto. Nesse sentido, o viés ortodoxo da agenda macroeconômica (leiam-se "tripé macroeconômico" e Novo Regime Fiscal) representa um grande obstáculo à adoção dessa agenda. Caso esse cenário não se altere, a tendência é de que se mantenha o entorpecimento do processo de desenvolvimento da economia, do Estado e, consequentemente, do setor industrial.

\section{Referências}

AZZONI, C. R. Indústria e reversão da polarização no Brasil. Ensaios Econômicos, São Paulo, IPE-USP, n. 58, 1986.

BENKO, G. Economia, espaço e globalização. 2. ed. São Paulo: Hucitec, 1999.

BIELSCHOWSKY, R. Cinquenta anos do pensamento na Cepal - Uma resenha. In: BIELSCHOWSKY, R. Cinquenta anos do pensamento na Cepal. Rio de Janeiro: Record, 2000. v. 1.

BRESSER-PEREIRA, L. C.; MARCONI, N. Existe doença holandesa no Brasil? In: BRESSERPEREIRA, L. C. (org.). Doença holandesa e indústria. Rio de Janeiro: Fundação Getulio Vargas, 2010.

CAIADO, S. C. Desconcentração industrial regional no Brasil (1985-1998): pausa ou retrocesso? 2002. Tese (Doutorado em Economia) - Instituto de Economia, Universidade Estadual de Campinas, Campinas, 2002.

CANO, W. Novas determinações sobre as questões regional e urbana após 1980. Revista brasileira de estudos urbanos e regionais, v. 13, n. 1, p. 27-53, 2011.

CAVALCANTE, L. R. Classificações tecnológicas: uma sistematização. Nota técnica n. 17. Brasília, DF: Ipea, mar. 2014. p. 1-21.

CLARK, C. The conditions of economic progress. London: Macmillan, 1957.

CRUZ, B. de D.; SANTOS, Y. R. S. dos. Dinâmica do emprego industrial no Brasil entre 1990 e 2007: uma visão regional da desindustrialização. Boletim Regional, Urbano e Ambiental. Brasília, DF: Ipea, 2009. v. 2.

DE NEGRI, F.; CAVALCANTE, L. R. (org.) Produtividade no Brasil: desempenho e determinantes. Brasília, DF: ABDI-Ipea, 2014.

DINIZ, C. C. Desenvolvimento poligonal no Brasil: nem desconcentração, nem contínua polarização. Nova Economia, v. 3, n. 1, p. 35-64, 1993.

Celso Furtado e o desenvolvimento regional. Nova econ., v. 19, n. 2, p. 227-249, 2009. Versão online. 
DINIZ, C. C. Corrida científica e tecnológica e reestruturação produtiva: impactos geoeconômicos e geopolíticos. Revista brasileira de estudos urbanos e regionais, v. 21, n. 2, p. 241-257, maio-ago. 2019.

DINIZ, C. C.; MENDES, P. S. Tendências regionais da indústria brasileira no século XXI. Brasília, DF: Ipea, 2021. p. 7-45. (Texto para discussão, n. 2640).

FURTADO, C. Análise do “modelo” brasileiro. Rio de Janeiro: Civilização Brasileira, 1972. Brasil: A construção interrompida. Rio de Janeiro: Paz e Terra, 1992. Desenvolvimento e subdesenvolvimento. Rio de Janeiro: Contraponto, 2009.

GÓIS-SOBRINHO, E. M. A localização e o grau inovativo das aglomerações industriais relevantes do Brasil. 2014. Dissertação (Mestrado) - Instituto de Pesquisas Econômicas, Universidade de São Paulo, São Paulo, 2014.

HATZICHRONOGLOU, T. Revision of the high-technology sector and product classification. OECD Science, Technology and Industry Working Papers, 1997. (Working paper, n. 1997/02).

HERRENDORF, B.; ROGERSON, R.; VALENTINYI, Á. Growth and structural transformation. In: AGHION, P.; DURLAUF, S. N. (ed.). Handbook of Economic Growth. Amsterdam: Elsevier B. V. 2014. p. $855-941$.

HIRSCH-KREINSEN, H.; JACOBSON, D.; LAESTADIUS, S.; SMITH, K. Low-tech industries and the knowledge economy: State of the art and research challenges. Artigo do projeto Policy and Innovation in Low-Tech - Pilot, 2003. Disponível em: http://pilot-project.org/ publications/sota2.pdf. Acesso em: 17 jul. 2019.

IBGE. Contas regionais do Brasil. Rio de Janeiro: IBGE, vários anos. Disponível em: https:// www.ibge.gov.br/estatisticas/economicas/contas-nacionais/9054-contas-regionais-do-brasil.html?. Acesso em: 14 set. 2019.

Pesquisa Industrial Anual. Rio de Janeiro: IBGE, vários anos. Disponível em: https://www.ibge.gov.br/estatisticas/economicas/industria/9042-pesquisa-industrial-anual.html?=\&t=o-que-e. Acesso em: 13 jul. 2021.

Pesquisa Industrial de Inovação Tecnológica - PINTEC. Rio de Janeiro: IBGE, vários anos. Disponível em: https://www.ibge.gov.br/estatisticas/multidominio/ciencia-tecnologia-e-inovacao/9141-pesquisa-de-inovacao.html?=\&t=o-que-e. Acesso em: 13 jul. 2021.

OREIRO, J. L.; FEIJÓ, C. A. Desindustrialização: conceituação, causas, efeitos e o caso brasileiro. Revista de Economia Política, v. 30, n. 2, p. 219-232, 2010.

MONTEIRO NETO, A.; SILVA, R.; SEVERIAN, D. Região e indústria no Brasil: ainda a continuidade da "desconcentração concentrada"? Economia e Sociedade, v. 29, n. 2, 2020.

MORCEIRO, P. C.; GUILHOTO, J. M. Desindustrialização setorial e estagnação de longo prazo na manufatura brasileira. Nereus/USP, TD n. 1, 2019.

PALMA, G. Four sources of de-industrialization and a new concept of the Dutch disease”. In: OCAMPO, J. A. Beyond reforms, structural dynamics and macroeconomic vulnerability. Stanford: Stanford University Press, 2005. chap. 3, p. 71-116. 
RIBEIRO, C. G.; INACIO JUNIOR, E.; LI, Y.; FURTADO, A.; GARDIM, N. The influence of user-supplier relationship on innovation dynamics of Oil \& Gas industry. Technology Analysis \& Strategic Management, v. 0, n. 0, p. 1-14, 2019.

RODRIK, D. Premature deindustrialization. Journal of Economic Growth, v. 21, n. 1, p. 1-33, 2016.

ROWTHORN, R. Manufacturing in the world economy. Economie Appliquée, t. L, n. 4, p. 63-96, 1997.

SAMPAIO, D. P. Desindustrialização e desenvolvimento regional no Brasil (1985-2015). In: MONTEIRO NETO, A.; CASTRO, C. N.; BRANDÃO, C. A. (org.). Desenvolvimento regional no Brasil: políticas, estratégias e perspectivas. Brasília, DF: Ipea, 2017.

TREGENNA, F. Characterising deindustrialisation: An analysis of changes in manufacturing employment and output internationally. Cambridge Journal of Economics, v. 33, issue 3, p. 433-466, 2009.

Deindustrialization and premature deindustrialization. In: REINERT, E.; GHOSH, J.; KATTEL, R. (org.). Handbook of alternative theories of economic development. Cheltenham, UK: Edward Elgar Publishing, 2016.

VON TUNZELMANN, N.; ACHA, V. Innovation in "low-tech" industries. In: FAGERBERG, J.; MOWERY, D. C.; NELSON, R. R. (ed.). The Oxford Handbook of Innovation. Oxford: Oxford University Press, 2005. p. 407-432. 


\section{Cássio Garcia Ribeiro}

Graduado em Economia pela Universidade Estadual Paulista Júlio de Mesquita Filho (Unesp, 2001), com mestrado em Política Científica e Tecnológica pela Universidade Estadual de Campinas (Unicamp, 2005), doutorado pelo mesmo programa e instituição (2009) e pós-doutorado no Instituto de Economia, também da Unicamp (2020). É professor do Instituto de Economia e Relações Internacionais (Ieri) da Universidade Federal de Uberlândia (UFU), onde atua na graduação e na pós-graduação em Economia.

Email: cassiogarcia@ufu.br

ORCID: 0000-0001-9290-0660

Contribuição de autoria: conceituação; análise formal; investigação/pesquisa; metodologia; escrita - primeira redação; escrita - revisão e edição.

\section{Soraia Aparecida Cardozo}

Professora associada do Instituto de Economia e Relações Internacionais da Universidade Federal de Uberlândia (Ieri/UFU). Economista graduada pela Universidade Estadual de Campinas (Unicamp), mestre e doutora em Desenvolvimento Econômico pela mesma universidade, com pós-doutorado na School of Oriental and African Studies (SOAS), University of London.

Email: soraia.cardozo@ufu.br

ORCID: 0000-0001-5830-6879

Contribuição de autoria: conceituação; análise formal; investigação/pesquisa; escrita - primeira redação; escrita - revisão e edição. 


\section{Humberto Martins}

Professor titular do Instituto de Economia e Relações Internacionais da Universidade Federal de Uberlândia (Ieri/UFU). Graduado em Ciências Econômicas pela UFU, mestre em Geografia pela Universidade Federal de Minas Gerais (UFMG), doutor em Planejamento Urbano e Regional pela Universidade Federal do Rio de Janeiro (UFRJ), com pós-doutorado pela University of Cambridge.

Email: hmartins@ufu.br

ORCID: 0000-0003-4672-1594

Contribuição de autoria: conceituação; metodologia; escrita - primeira redação; escrita - revisão e edição.

Submissão: 6 de maio de 2021.

Aprovação: 19 de junho de 2021.

Como citar: RIBEIRO, C. G.; CARDOZO, S. A.; MARTINS, H. Dinâmica regional da indústria de transformação no Brasil (2000-2017). Revista brasileira de estudos urbanos e regionais. v. 23, E202120, 2021. DOI 10.22296/2317-1529.rbeur.202120

Artigo licenciado sob Licença Creative Commons CC BY 4.0. https://creativecommons.org/licenses/by/4.o/deed.pt_BR 